\title{
SEI QUE EXISTE, MAS NÃO QUERO VER: O PRECONCEITO COM CRIANÇAS NEGRAS NA EDUCAÇÃO INFANTIL
}

\author{
Lima, Thaísa de Oliveira \\ UFG/JATAÍ-thaisaol@yahoo.com.br
}

RESUMO:

Este artigo é resultado de uma pesquisa desenvolvida na disciplina de Trabalho de Conclusão de Curso (TCC), do curso de Pedagogia. Foi pensado ao longo do curso, mas, especialmente durante as atividades de práticas na disciplina de Estágio em Educação Infantil e Anos Inicias I e II, realizado em instituições de Educação Infantil (EI) na cidade de Jatai-Goiás. Tem como objetivos compreender como tem se constituído a inserção da criança negra nas instituições de EI jataiense; identificar existência ou não preconceitos em relação a criança negra nessa etapa de educação; verificar atitudes e comportamentos de socialização entre crianças negras e demais crianças da turma, corpo docente e demais funcionários da instituição. Inicialmente fizemos um estudo da produção bibliográfica sobre a inserção da criança negra em diferentes instituições de EI; desenvolvemos também observações em duas instituições de EI para verificar se existiam ou não preconceitos com as crianças nestas instituições, observando as atitudes entre as crianças, entre os adultos e as crianças em relação a algum tipo de preconceito racial. A pesquisa que serviu de base no presente trabalho teve abordagem qualitativa, visto que esta se preocupou com um nível de realidade que não podia ser quantificado. Trabalhamos com um universo de significações, motivos, aspirações, crenças, valores e atitudes, o que correspondia a um espaço mais profundo das relações, dos processos e dos fenômenos que não podiam ser reduzidos à operacionalização de variáveis. Os autores que embasam esta pesquisa foram: Borges Pereira (1987); Cavalleiro (2003, 2009); Jesus (2006); Trinidad (2009), dentre outros.

PALAVRAS-CHAVE: preconceito, educação infantil, diversidade cultural

\begin{abstract}
ABSTRAT
This article is the result of a research of Labour Final Course (CBT), discipline developed in complement to the course, University Federal de Goiás, Faculty of Education. It was designed along the course, particularly during activities such practices in the discipline of Stage and Years in Early Childhood Education Initiative I and II, conducted in early childhood education institutions (EI) in the city of Jatai-Goiás. It aims to understand how the inclusion of black children in the institutions of EI Jataiense; identify whether or not the biased against black children in this stage of education; verify attitudes and behaviors of socialization among black children and other children in the class, teachers and other employees of the institution. Initially we studied the production of literature on the inclusion of black children in different institutions of EI, we have also developed two observations EI institutions to verify
\end{abstract}


whether there were biases with the children in these institutions, observing the attitudes among children, among adults and children in relation to some kind of racial prejudice. The research that formed the basis of this study was a qualitative approach, as it was concerned with a level of reality that could not be quantified. We work with a universe of meanings, motives, aspirations, beliefs, values and attitudes, which reflected a deeper space of relations, processes and phenomena that could not be reduced to the operationalization of variables. Authors who support this research were: Borges Pereira (1987); Cavalleiro (2003, 2009), Jesus (2006), Trinidad (2009), among others.

KEY WORDS: discrimination, child education, cultural diversity

\section{INTRODUÇÃO}

O projeto que deu origem a esse artigo foi pensado ao longo do curso de Pedagogia, especialmente durante as atividades práticas nas disciplinas de Estágio I e II. Entretanto, ao longo do curso e da efetivação das disciplinas - 4 anos - diversas dúvidas surgiram em meu pensamento em relação ao Trabalho de Conclusão do Curso (TCC) que realizaríamos no último ano do mesmo. Mas, posso dizer que, durante e após as observações e regências realizadas nas disciplinas de Estágio em Educação Infantil e Anos Iniciais do Ensino Fundamental I e II, para a caracterização da instituição em que realizamos nosso projeto de estágio supervisionado, percebemos a importância de se planejar, no dia a dia, um trabalho que considerasse as crianças como integrantes de grupo socioculturais singulares, proporcionando a elas vivência de experiências que interagissem num contexto de conceitos, valores, ideias, objetos e representações sobre os mais diferentes temas a que têm acesso na vida cotidiana, tais como: preconceito, diversidade cultural, notícias da atualidade, histórias de outros tempos, dentre outros. Muitos são os temas que as crianças se interessam e que os educadores poderiam trabalhar de maneira integrada com outras atividades, mas determinados educadores observados parecem que não compreendem a importância de se trabalhar com tais enfoques.

Os cursos de Pedagogia têm acumulado considerável experiência e reflexão sobre as práticas por meio da disciplina de Estágio em Educação Infantil, através da qual os estudantes vão até as creches fazer observações e depois desenvolvem projetos 
na instituição em que ocorreram as primeiras observações. Nesse campo, são definidos os procedimentos mais adequados para se trabalhar esses projetos, sendo essas experiências desafiantes e as oportunidades de desenvolvimento e aprendizagem enriquecedoras. Como afirma Brandão (2005), entendemos que a educação não acontece somente na escola, mas no âmbito familiar, na comunidade em que vivemos, nas ruas, lugares que se frequentam, dentre outros. E, em todos esses lugares, deve-se respeitar cada um como ele o é, não fazendo diferenciação por cor, raça, sexo ou religião.

Ao falar sobre o racismo, Cavalleiro (2003) afirma que a interface racismo e educação oferece possibilidade de colocar, no mesmo palco, a importância de duas temáticas: a função social da escola e a diversidade cultural. Como sabemos, a escola, de um modo geral, constitui-se em um espaço de acomodações, de vivências e resistências. O espaço escolar, em alguns momentos, age de forma a reforçar as diferenças estabelecidas socialmente entre as diversidades culturais, ou seja, entre negros e brancos, crianças de religiões diferentes, países, possibilitando que novas relações sejam construídas paulatinamente.

Neste sentido, os preconceitos e as discriminações raciais produzidas por meio das relações entre educador/criança, criança/criança, funcionário/educadores, funcionário/crianças, funcionários/funcionários, principalmente, pelas imagens e conteúdos que são transmitidos por meio de recursos utilizados na instituição (revistas, Referencial Curricular Nacional da Educação Infantil (RCNEI), livros didáticos e paradidáticos...), em especial ao que diz respeito ao Ensino Fundamental, na maioria das vezes, reforçam a imagem inferiorizada do negro, do índio, mostrando o branco como superior aos demais, o que poderá resultar, futuramente, nas vidas dessas crianças, em fracasso escolar, marcando-as para o resto de suas vidas. Quando analisamos as relações raciais dentro da escola ou de uma instituição de Educação Infantil (EI), questionamos até que ponto está sendo coerente a função social da instituição, quando esta se propõe a ser um espaço de diversidade cultural e uma das responsáveis pela igualdade.

Segundo Jesus (2006), citando a socióloga Alice Itani, o preconceito étnico faz parte do comportamento do cotidiano de cada um. Ela afirma também que "os negros se defrontam constantemente com atitudes preconceituosas, seja em atos ou 
gestos, discursos e palavras” (2006, p.1); daí subjaz que o preconceito étnico é o que se encontra mais presente na sociedade brasileira, constantemente na prática escolar e aqui destacaremos nas instituições de Educação Infantil (EI), o qual foi o alvo da nossa pesquisa.

Para Cavalleiro (2003), a formação dos futuros profissionais - e até mesmo dos profissionais que atuam nas instituições escolares -, para que tratem com respeito e dignidade as diferenças raciais no âmbito escolar, contribuindo para o enfrentamento e a superação das desigualdades, precisa incorporar novos valores nos profissionais que lidam com as crianças e, consequentemente, em seus familiares.

Conforme Trinidad (2009), diferentes instituições, como “Movimento Negro no Brasil” e, especificamente, no município de São Paulo, “CEERT, Fala Preta!”, “Geledés”, organizações não-governamentais que atuam na formação sobre relações raciais desde a década de 1990, entre outras, desenvolveram quantidades significativas de processos formativos entre as pessoas. Conforme pesquisas atuais feitas por essas entidades, as desigualdades raciais persistem; nesse sentido, entendemos que o racismo está se revestindo com uma nova "roupagem" e, para isso, será necessário o desenvolvimento de novas “armas” para enfrentá-lo, principalmente no ambiente escolar.

Uma das estratégias que pode ser trabalhada é sobre as diferenças raciais, começando com crianças desde muito pequenas. Em um primeiro momento, seria necessário trabalhar os temas desde a formação inicial específica de educadores que atuarão nas instituições de EI, como afirmamos anteriormente, considerando que a faixa etária de 0 a 5 anos é fundamental na formação da personalidade humana. Necessário, também, trabalhar a questão da formação continuada para aqueles profissionais que já atuam nas instituições. Pesquisadores que estudam essa etapa da vida, afirmam que esta fase se configura como uma das mais importantes para o processo da construção da identidade. Trinidad (sd), citando Bergman \& Luckman (1985), afirma que nesse período da vida ocorre o processo de socialização primária, em que as crianças [...] “assumem” o mundo no qual os outros já vivem [...] “compreendendo” os processos subjetivos momentâneos do outro, mas “compreendendo” o mundo em que vivem e esse 
mundo em que vivem torna-se o seu próprio (Trinidad apud Bergman \& Luckman, 1985).

Entendemos que a instituição escolar é responsável pelo processo de socialização da criança, pois ela irá se relacionar com crianças de diferentes famílias, o que favorece a construção de sua identidade. O contato que as crianças têm na instituição infantil pode ser o primeiro contato das vivências das diversidades culturais, e, nessa fase, elas refletem gradativamente e tomam consciência do mundo, de diferentes maneiras, em cada etapa de seu desenvolvimento. Como afirma o RCNEI (1998), as transformações que ocorrem no pensamento da criança se dão simultaneamente ao desenvolvimento da linguagem e de suas capacidades de expressão. À medida em que a criança cresce, depara-se com fenômenos, fatos e objetos do mundo; perguntam, reúnem informações, organizam explicações e arriscam respostas; essas questões são fundamentais para seu modo de conceber a natureza e a cultura, ou seja, entender e interagir com o outro.

O educador deve ter muito cuidado em suas falas com as crianças, pois pode ser, em uma fala mal interpretada, que esta passe a ver a criança negra como feia, suja, do cabelo ruim. São usuais as expressões: "vamos tomar banho porque estão pretos de sujeiras”, "hoje a coisa tá preta”, dentre outras; isso pode levar ao processo de desvalorização de outras crianças, interferindo na construção de sua identidade de criança. Por isso, o educador deve atentar-se aos seus valores étnicos, preocupando-se com expressões, com gestos, porque eles também falam por si; é preciso se interessar por estudos sobre crianças afro-descendentes, histórias de outros tempos - nossos antepassados -, para que tenham propostas e práticas educativas diversas, que partam da ideia de falar da diversidade cultural, social, geográfica e histórica. Muitas vezes, são negadas propostas valiosas de trabalho, as quais contribuem para que as crianças reflitam sobre os distintos modos de ver e de ser.

Jesus (2006) diz que a ausência do componente negro na instituição educativa priva as crianças negras de conhecerem a sua história, que vai muito além da escravidão. A instituição escolar necessita reformular, com urgência, seu plano de curso, assim como os conteúdos e problematizar a questão do negro em seus contextos.

Para Cavalleiro (2003): 
Há todo um aparato para representar e valorizar a criança, a família e o profissional branco e não há o mesmo em relação ao negro. O que mais me chamou atenção foi o jeito debochado dos professores no contato com as crianças negras. Facilmente esses alunos são chamados de "Filhotes de São Benedito" ou "cães em figura de gente”. Esses comentários não costumam ser diretos, mais é comum que um professor fale para outro, quando a criança está passando. Elas se divertem se percebem que a criança ouviu (Cavalleiro, 2003, p.38).

Esta observação da autora remete-nos às observações realizadas nas instituições de EI durante o estágio, visto que não é difícil percebermos o lugar do negro nos espaços escolares; sendo assim, muitas crianças registram certas falas maldosas que escutam dos adultos e acabam carregando pelo resto da vida, criando traumas, acreditando que são incapazes, inferiores às outras pessoas, e qualquer dificuldade que encontram no decorrer dos estudos, acabam abandonando a escola, sem dizer outras situações de baixa auto-estima que carregarão pelo resto da vida.

Borges Pereira (1987) diz que:

\begin{abstract}
É de conhecimento comum que a socialização em sociedades complexas, como a brasileira, se dá de forma espontânea e sistemática. A espontânea, como se sabe, apanha o indivíduo ao nascer e o envolve até a morte. As agências corriqueiramente citadas como responsáveis por esse processo socializador confundem-se com os chamados grupos primários em diferentes graus de institucionalização e, às vezes, com distintas metas sociais (...). A essa relação de grupos são costumeiramente incluídos, também, desde agências tradicionais formadoras de opinião, como por exemplo, a igreja e a imprensa, até os mais persuasivos e modernos mecanismos de comunicação social, como o cinema, o rádio e a tevê, que influenciam e moldam pessoas e grupos sociais atuando tanto em ambientes fechados como em locais públicos. Para usar uma expressão, ao mesmo tempo tipológica e simbólica, tais mecanismos estão presentes tanto na casa como na rua (Borges Pereira, 1987, p. 41, grifos no original).
\end{abstract}

As experiências educativas que a criança passa, ampliam e intensificam a sua socialização. Nesse sentido, é interessante esse contato com outras crianças e adultos que não são do seu meio familiar. Essas novas experiências serão positivas para o desenvolvimento da criança, e, desta forma, afirmamos que as instituições de EI (creches e pré-escolas) e demais instituições de educação podem ser o lugar de 
desenvolver trabalhos com possibilidades de evitar a interiorização de comportamentos e atitudes preconceituosas e discriminatórias contra os negros. É preciso que os educadores trabalhem com ações que levem as crianças a entenderem a aceitação positiva e valorizada das crianças negras no seu cotidiano, afirmando seu processo de convivência e socialização.

\section{DESENVOLVIMENTO METODOLÓGICO}

Este trabalho teve como objetivo analisar as relações de preconceito com crianças negras em duas instituições de educação infantil. Utilizamos diferentes obras de autores que estudam atitudes de preconceito étnico-racial que comprometem a identidade e a auto-estima da criança negra, contribuindo com o processo de exclusão social. Segundo Ludke e Andrë (1986), no texto "Pesquisa em educação: abordagens qualitativas”, a metodologia é o caminho do pensamento e a prática exercida na abordagem da realidade. Ela inclui um conjunto de técnicas que possibilitam a construção da realidade. A teoria e a metodologia devem caminhar juntas. A metodologia deve dispor de um instrumental claro, coerente, elaborado, capaz de encaminhar os impasses teóricos para o desafio da prática.

Assim, a pesquisa que serviu de base para o presente trabalho teve abordagem qualitativa, visto que esta se preocupou com um nível de realidade que não podia ser quantificado. Trabalhamos com um universo de significações, motivos, aspirações, crenças, valores e atitudes, o que correspondia a um espaço mais profundo das relações, dos processos e dos fenômenos, que não podiam ser reduzidos à operacionalização de variáveis. A abordagem qualitativa aprofunda-se no mundo dos significados das ações e relações humanas, um lado não perceptível e não captável em equações, médias e estatísticas. Isto é, não podemos medir e nem quantificar as atitudes de preconceito ou não com crianças negras na EI.

Utilizamos como instrumentos de pesquisa a observação e registros no diário de campo, pois o trabalho foi pensado tendo em vista o acompanhamento das pessoas no convívio social, em suas relações multiétnicas no espaço pré-escolar. Desta maneira, 
procuramos apreender como as crianças lidam com suas primeiras experiências multiétnicas, como pensam sobre elas e como as elaboram. Observamos as relações do professor/criança, criança/criança e demais profissionais/criança. Não basta apenas perguntar ao professor como se dá o seu relacionamento com as crianças, ou entre elas, é necessário vê-lo na sua prática profissional, no seu dia-a-dia. Observamos também a vivência das relações interpessoais nas instituições pesquisadas, essencialmente quando se entende a educação como um dos elementos principais e seus fatores de desenvolvimento pessoal e de grupo.

FORMAÇÃO DO PROFESSOR PARA O TRABALHO COM DIVERSIDADE: ALGUMAS CONSIDERAÇÕES

Diferentes autores abordam a questão de negro na educação; porém, na EI, ainda são poucos os autores que trabalham com esse tema, especialmente sobre o preconceito que as crianças menores de cinco anos sofrem em instituições coletivas. Os conflitos vividos pelas pessoas negras no dia-a-dia, os preconceitos que sofrem, a construção de uma imagem negativa, podem gerar conflitos na formação de sua identidade pessoal. Martins e Munhós (2007) relatam que, "se o negro é retratado como sinônimo daquilo que é desvalorizado na sociedade, seria compreensível que as crianças negras não queiram se identificar com esse valor” (2007, p.19).

Com essa pesquisa, percebemos que o grande entrave reside na formação dos profissionais da área da Educação, que não enfoca a questão do preconceito ou da diversidade cultural. No entanto, em termos de políticas públicas, presenciamos alguns indicadores de mudança e inclusão da temática afro-brasileira nos currículos no ensino fundamental, não contemplando, porém, a EI. Precisamos reconhecer que ainda há limitações na formação dos educadores em relação a essa temática.

Verifica-se a ausência dessas temáticas tanto na formação inicial quanto continuada dos profissionais da educação; prova disso é que no curso de Pedagogia (UFG-CAJ), durante os quatro anos - período em que o cursamos - a única disciplina que nos possibilitou a discussão desse tema foi um núcleo livre oferecido no período de verão (férias), intitulado: “Educação e diversidade étnico-racial”, o que, por não ser uma 
disciplina obrigatória e ainda oferecida nesse período, muitos alunos saem de férias, viajam ou não se interessam; somente aqueles que realmente se interessavam pelo assunto é que procuraram pela mesma.

Os professores que atuam nas instituições de EI devem ser preparados para vivenciar as realidades e, acima de tudo, aceitar a diferença das crianças que fazem parte do contexto da instituição. Presenciamos muitas diferenças no tratamento das crianças negras e brancas, muitas vezes “taxadas” por situações que acontecem sem mesmo terem como se defender, ao que entendemos que isso seja ocasionado pelo preconceito.

Apesar de todos os acontecimentos que presenciamos durante a pesquisa mencionada, acreditamos que a educação é uma grande aliada na luta contra os preconceitos raciais; a escola deve ser o local em que não se pode negar a transmissão dos conhecimentos desenvolvidos e produzidos pela humanidade, tampouco a intencionalidade do ato educativo. Dessa forma, questões como preconceitos deveriam ser vividas e debatidas com mais ênfase, entretanto, percebemos ausência desses debates nas instituições de ensino superior e no dia-a-dia do trabalho das profissionais de EI.

Percebemos que muitas crianças negras, na instituição de EI, ainda sofrem preconceitos, tanto por profissionais da instituição como das próprias crianças que estão ali inseridas, como por exemplo, a cor da pele, do cabelo, dentre outros. Vimos o professor não se manifestar diante de determinadas situações que ocorreram durante nossas observações; o silêncio do professor, quando ocorre manifestações de preconceito racial, mostra o despreparo para lidar com situações de discriminações raciais.

Trabalhar com a socialização de crianças de zero a cinco anos é trabalhar com a etapa fundamental e inicial do desenvolvimento humano. A educação recebida pela criança na instituição educativa é significativa para o seu desenvolvimento futuro como sujeito social, porém, essa socialização deve ocorrer primeiramente em uma tarefa familiar. Cavalleiro (2003), citando Caparrós (1981), afirma que é da família que saem os "possuidores, o comunista, a mulher passiva, o dominado e o dominador. (...) as futuras relações, homem/mulher, tanto em autovalorização e valorização do outro, já 
estão ideologicamente plantadas em semelhança às dos adultos” (2003, p. 16). Entretanto, não se pode abrir mão do papel da instituição escolar também. É como vimos no depoimento da professora, ao contar sobre uma criança considerada branca que não quis pegar na mão de outra criança por ser negra. Quando a professora falou com a mãe, que também é professora na instituição, a resposta foi: “A mãe da criança acha que sua filha não tem preconceito, é apenas uma questão de gosto”. Sendo assim, cabe ao educador trabalhar essas questões com as crianças.

Diversos livros literários podem ser trabalhados com as crianças, como o livro "Menina bonita do laço de fita”, de Ana Maria Machado, “Tanto, tanto”, de Trish Cooke e Helen Oxenbury, "Betina”, de Nilma Lino Gomes, dentre outros. O professor pode fazer um trabalho diferenciado juntamente com os pais e a comunidade, chamando aqueles que gostam de contar história para irem até à instituição, levando suas experiências, suas vivências, sua história, permitindo, assim, que a criança sinta-se mais valorizada. A educadora pode trabalhar com as crianças as origens dos negros, de uma forma simples e educativa, estudando o tipo de roupas que eles vestem, suas músicas, comida, as histórias, ou seja, questões que crianças, a partir dos 3 anos, já começaram a entender e que permitem que seja desenvolvido o respeito ao próximo.

Experiências educativas que a criança vivencia, amplificam na sua socialização; o contato com as outras crianças e outros adultos é importante, pois terão e passarão por novas experiências, as quais serão positivas para o desenvolvimento delas. Desta forma, afirmamos que as instituições de EI (creches e pré-escolas) e demais instituições de educação podem ser um dos melhores lugares de seu desenvolvimento dessas experiências. Os trabalhos que os educadores podem fazer com as crianças possibilitarão e evitarão a interiorização de comportamentos e atitudes preconceituosas e discriminatórias contra os negros. Faz-se necessário que os educadores trabalhem com ações que levem as crianças a entender a aceitação positiva e valorizada das crianças negras no seu cotidiano, afirmando seu processo de convivência e socialização.

Borges Pereira (1987) diz que o conhecimento que adquirimos no dia-a-dia, na convivência, na socialização, dá-se de forma espontânea e sistemática. A espontânea apanha o indivíduo ao nascer e o envolve até a morte. Existem também as agências, corriqueiramente como responsáveis por esse processo socializador, as quais são 
chamadas grupos primários, em diferentes graus de institucionalização e, muitas vezes, com distintas metas sociais. E relação de grupos são costumeiramente incluídos, também, desde agências tradicionais formadoras de opinião, como por exemplo, as igrejas e a imprensa, até mesmo os mais persuasivos e modernos mecanismos de comunicação social, como a TV, o cinema, o rádio, a internet, que influenciam e moldam pessoas e grupos sociais que atuam tanto em ambientes fechados como em locais públicos.

Formosinho (s/d), em seu texto "Diversidade cultural na escola de massas: abordagens à educação multi/intercultural”, diz que a escola é um instrumento decisivo na construção ou consolidação das nações de todo o mundo. Desta forma, a inclusão de valores nacionalistas é essencial na educação escolar, pois incentivam uma pedagogia homogeneizadora das diferenças. Nesse sentido, é urgente e inquestionável a necessidade de capacitação de professores que trabalhem a questão étnica racial, como também a história e cultura afro-brasileira no currículo e que isso não aconteça apenas no dia 20 de novembro, no calendário escolar, o qual é destinado como Dia Nacional da Consciência Negra. Esta qualificação consiste na elaboração de materiais didáticos que darão suporte técnico na formação inicial e continuada dos professores. Desta forma, tratar a temática do negro no currículo escolar independe do professor ser negro ou não. A lei $n^{0} 10.639 / 2003$ existe para ser cumprida, não apenas para ser uma letra morta no ordenamento jurídico brasileiro, tendo função estratégica na formação do cidadão brasileiro, mas cabe ao educador trabalhar sobre essas temáticas.

Existe uma série de distorções históricas que alimentam as práticas inferiorizadas das culturas, principalmente a cultura afro, e estas estão manifestadas no meio social e no ambiente escolar. Também existe uma série de mitos e inverdades sobre os negros, ou melhor, sobre a origem dos negros, como por exemplo, a questão de “cabelo ruim é de negro”, que “negro não trabalha”, que é “preguiçoso”, é “ladrão”, dentre outros. Esses mitos e inverdades afetam a construção de uma sociedade verdadeiramente democrática e penalizam a população negra, pois demonstram uma imagem negativa do negro, dos africanos e dos afro-descendentes, cuja veiculação na sociedade resulta em barreiras para a construção e exercício da cidadania. 
É urgente e inquestionável a necessidade de capacitação do educador, de forma que possam, também, cumprir a lei $n^{\circ} 10.639 / 2003$, a qual não tem sido trabalhada como foi proposta. Os educadores precisam trabalhar sobre as questões raciais e, com isso, elaborar materiais didáticos que possam dar suporte técnico na formação inicial e continuada de professores, seja na Educação Infantil, Ensino Fundamental ou Ensino Médio.

Em suma, percebemos que falta, ainda, aos educadores, preparação adequada para que possam trabalhar as questões raciais com crianças na EI. Sentimos grande dificuldades, vinda dos professores, quando se deparavam com problemas voltados aos preconceitos e também professores que demonstravam preconceitos com crianças negras - mas que diziam não ter preconceitos - e aqueles que achavam que a forma de falar, principalmente do cabelo das crianças, especialmente depois do banho, momento em que as professoras penteavam os cabelos das crianças, não era preconceituosa. Vimos, nos rostos das crianças, tristeza, além do que, essas nem sabiam como reagir quando se dizia algo sobre o cabelo. Enfim, entendemos que, para responder a esse desafio que se apresenta em relação as atitudes preconceituosas e ao atendimento da legislação mencionada, faz-se necessário atuar no combate a todas as formas de preconceito e racismos. É urgente fortalecer a nação brasileira em torno da democracia, da diversidade cultural e esse é objetivo fundante das políticas públicas e dos órgãos gestores da educação e, nesse caso específico, das unidades formadoras de profissionais que se dedicam diretamente com o fenômeno educativo.

\section{REFERÊNCIAS:}

BRANDÃO, Carlos Rodrigues. O que é educação. São Paulo: Editora Brasiliense. 2005

BRASIL, Ministério da Educação e do Desporto. Secretaria de Educação Fundamental. Referencial Curricular Nacional para a Educação Infantil. Brasília: MEC/SEF, 1998.

Lei $\mathrm{n}^{\circ}$ 9.394/96, de 20 dezembro, 1996. Estabelece as diretrizes e bases da educação nacional. Diário Oficial da União. Brasília: 20 dezembro, 1996. 
BORGES PEREIRA, J. B. A criança negra: identidade étnica e socialização. In: Cadernos de Pesquisa. (n.63, p.41-5) São Paulo, 1987.

CAVALLEIRO, Eliane dos Santos. Do silêncio do lar ao silêncio escolar: racismo, preconceito e discriminação na educação infantil. São Paulo: Contexto, 2003.

- Diversidade racial e desigualdade na educação infantil. http://www.acmun.org.br/artigos/drdi.htm. Acessado em 12/02/2009

FORMOSINHO, João. Diversidade cultural na escola de massas: abordagens à educação multi/intercultural. SD.

LUDKE, Menga; ANDRË, Marli E. D. Pesquisa em educação: abordagens qualitativas. São Paulo: EPU, 1986.

JESUS, Elisângela Maria de. Escola: espaço para construção da identidade da criança negra. http://www.paralerepensar.com.br/elisangela_criancanegra.htm. Acessado em 24/01/2009. Publicação10/07/2006: www.paralerepensar.com.br

MARTINS, Roseli Figueiredo; MUNHOZ, Maria Leticia Puglisi. Professora, não quero brincar com aquela negrinha!. São Paulo: Ministério da Educação, 2007.

TRINIDAD, Cristina Teodoro. Formação docente para educação infantil: políticas e metodologias para promoção da igualdade racial. http://www.controlesocial.org.br/boletim/ebul21/fai_amarelo1.html. Acessado em 24/01/09. 